\title{
Shock compression response of nanoiron powder compact
}

\author{
Chengda Dai, ${ }^{\text {a) }}$ Daniel Eakins, and Naresh Thadhani \\ School of Materials Science and Engineering, Georgia Institute of Technology, Atlanta, Georgia 30332
}

\author{
J. Ping Liu \\ Department of Physics, University of Texas at Arlington, Arlington, Texas 76019
}

(Received 20 November 2006; accepted 17 January 2007; published online 15 February 2007)

\begin{abstract}
The shock compression response of nano-Fe powder $(\sim 25 \mathrm{~nm})$ pressed to $\sim 35 \%$ theoretical maximum density was determined based on shock stress and wave velocity measurements using piezoelectric stress gauges. The obtained data show a discontinuity in shock wave velocity plotted against particle velocity and an inflexion in specific volume from compression to expansion with increasing shock stress. It is found that the Hugoniot of $25 \mathrm{~nm} \mathrm{Fe} \mathrm{powder} \mathrm{cannot} \mathrm{be} \mathrm{fully} \mathrm{described}$ using analytical models that are otherwise capable of predicting the Hugoniot of micron-sized powder or highly porous materials. (C) 2007 American Institute of Physics.
\end{abstract}

[DOI: $10.1063 / 1.2695522]$

Shock compaction has often been considered as a possible route for powder consolidation in order to fabricate bulk compacts. ${ }^{1}$ Shock consolidation involves densification and bonding of particles, accomplished by the passage of a shock wave through powder of certain initial density. The Hugoniot of the powder is crucial for reliable design of shock compaction experiments and for evaluation of the loading stress or pressure. In addition, the Hugoniot of powder compacts of varied porosities possesses important significance in constructing the equation of state over a wide range of density and temperature. ${ }^{2}$ However, it is not practical to measure the Hugoniot of prepressed powder with varied porosities. Thus, different analytical models, such as the model by McQueen et al. ${ }^{3}$ and Wu-Jing model, ${ }^{4}$ have been developed to predict the Hugoniot of porous materials or micron-scale powders prepressed to a certain initial density. These models, however, disregard the difference in specific internal energy between the powder and the corresponding polycrystalline solid. Hence, it is uncertain if these models can still be applicable for predicting the Hugoniot of nanosized powder. There exists no shock Hugoniot data of nanoscale particles available for model validation. In the current work, we used piezoelectric stress gauges to measure the shock stress and wave velocity in $\mathrm{Fe}$ nanoparticles prepressed to $\sim 35 \%$ theoretical maximum density (TMD). The obtained Hugoniot data were compared with the results from model calculations.

The nanopowder used was commercially available $25 \mathrm{~nm}$ Fe particles. The particles were of spherical morphology and a TMD of $\sim 7.85 \mathrm{~g} / \mathrm{cm}^{3}$. The nanopowder was prepressed to $\sim 35 \%$ TMD in a copper capsule consisting of driver and ring, and backed by a disk of polymethylmethacrylate (PMMA). The packing and pressing of powder were performed in Ar gas environment to prevent the oxidation of Fe nanoparticles. Polyvinylidene fluoride (PVDF) piezoelectric stress gauges ${ }^{5}$ were embedded between the $\mathrm{Cu}$ driver and the powder compact interface to measure the input stress and between the powder and PMMA backer to measure the propagated stress. The assembly is shown schematically in Fig. 1. The input and propagated gauges sandwich-

\footnotetext{
${ }^{a)}$ Electronic mail: chengda.dai@mse.gatech.edu
}

ing the sample of known thickness also allowed a measurement of the shock wave velocity. The PVDF gauge packages consisting of an insulating film of Teflon $(\sim 25 \mu \mathrm{m}$ thick) on both sides of an $\sim 25 \mu \mathrm{m}$ thick PVDF element $\left(3 \times 3 \mathrm{~mm}^{2}\right)$ were epoxy mounted with a bond thickness of 2-4 $\mu \mathrm{m}$. Aluminum deposition of $\sim 150 \mathrm{~nm}$ on the powder sides of the gauge package was utilized to prevent pyroelectric effects from affecting the gauge response during shock loading. The projectile velocity was measured using four inline shorting pins. The piezoelectric gauge was connected to a current viewing resistor and recorded on a digital oscilloscope with a sampling rate of $1 \mathrm{GHz}$. The PVDF gauges provided a current-time profile of 1 ns resolution, which was then numerically integrated to obtain the stress-time trace. The $80 \mathrm{~mm}$ diameter single-stage light-gas gun at GaTech was utilized for performing the shock experiments. Copper or tungsten was used as the flyer plate to acquire the desired shock stress in the sample. The details of the experimental procedures, measurement method, and data analysis were described elsewhere. ${ }^{6,7}$

Six shock experiments were performed to measure the stresses $\left(\sigma_{x}\right)$ and shock wave velocities $(D)$. Typical stresstime traces recorded by the input and propagated gauges are shown in Fig. 2. Both the input and propagated stress traces show fast rise times (see Table I) and a weak elastic precursor at lower stress (see Fig. 2). The time interval $(\Delta t)$ used to calculate $D$ was taken by averaging the three transit times at $10 \%, 50 \%$, and $90 \%$ of maximum stress amplitude. The maximal deviation in the average from the three transit times was regarded as the uncertainty of $\Delta t$. As a first-order approximation, the particle velocity $(u)$ was determined using the jump condition: $u=\sigma_{x} /\left(\rho_{00} D\right),{ }^{3}$ where $\rho_{00}$ is the prepressed powder density. The compressed density $(\rho)$ was obtained using $\rho=\rho_{00} D /(D-u){ }^{3}$ The raw data for all the Hugoniot experiments are given in Table I. The measured $D$ is plotted, respectively, against calculated $u$ and measured $\sigma_{x}$ in Figs. 3(a) and 3(b). As shown in Fig. 3(a), the $D-u$ Hugoniot of $\sim 35 \%$ TMD $25 \mathrm{~nm}$ Fe consists of two distinct segments: $D=-0.83+3.1 u$ for $\sim 0.65<u<\sim 0.9 \mathrm{~km} / \mathrm{s}$ and $D=0.82+0.56 u$ for $\sim 0.35<u \leqslant \sim 0.65 \mathrm{~km} / \mathrm{s}$. The stress corresponding to the transition of two $D(u)$ linear relations is $\sim 2 \mathrm{GPa}$. The negative $C_{0}$ and higher $S$ value in the range 

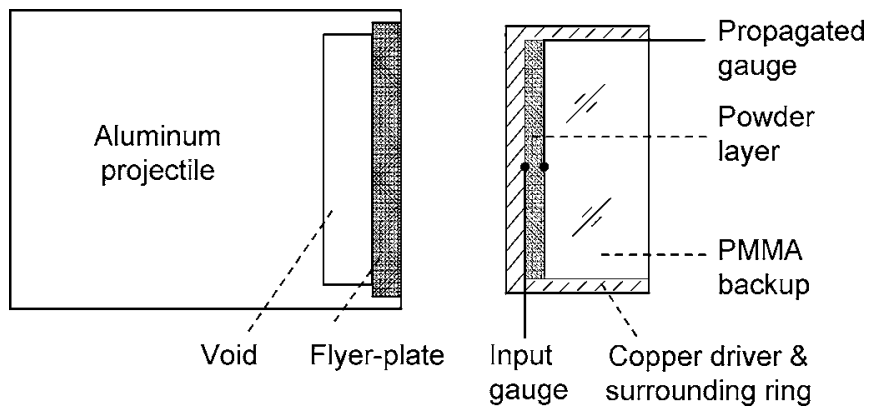

FIG. 1. Experimental configuration used for Hugoniot measurements with piezoelectric stress gauges sandwiching the powder sample for recording the input and propagated stress profiles and wave velocity. The typical dimensions are $\phi 57$ (in diameter thereinafter) $\times \sim 6.3$ (in thickness thereinafter) $\mathrm{mm}^{3}$ for $\mathrm{Cu}$ driver, $\phi 57 \times \sim 17.7 \mathrm{~mm}^{3}$ for $\mathrm{Cu}$ ring, $\phi 50.84 \times \sim 16.9 \mathrm{~mm}^{3}$ for PMMA, $\phi 57 \times \sim 9.5 \mathrm{~mm}^{3}$ for Cu flyer, $\phi 57 \times \sim 5.2 \mathrm{~mm}^{3}$ for tungstenflyer, and $\phi 50.84 \times 2 \sim 2.5 \mathrm{~mm}^{3}$ for powder compact, respectively.

of higher stresses are possibly a result of thermal effect or some other form of inhomogeneous mode of localized deformation such as shear banding. Figure 3(b) shows that the calculated $D\left(\sigma_{x}\right)$ curve based on the jump conditions is consistent with the directly measured data, implying that the observed shock state is quasisteady and the jump conditions are approximately appropriate to extract other shock state quantities from the observed stress traces.

We calculated the Hugoniot of 35\% TMD Fe powder using the Wu-Jing approach ${ }^{4}$ and compared it with the experimental results to examine the applicability of this model for predicting the Hugoniot of $\mathrm{Fe}$ nanopowder. Employing the Wu-Jing approach, we considered two cases: (a) neglecting the powder strength and (b) considering the strength. For case (a), the strength of matrix material, $Y$, which is equivalent to the void collapse strength or the full-consolidation stress, is assumed to be negligible $(Y \approx 0)$. The specific volume on the zero-Kelvin isotherm of the prepressed powder $\left(V_{C}^{\prime}\right)$ can be approximately regarded as that $\left(V_{C}\right)$ of solid at any given pressure due to $Y \approx 0$ based on the Carroll-Holt model. ${ }^{8}$ Also, the pressure of pre-pressed powder at Hugoniot elastic limit is assumed negligible $\left(P_{1} \approx 0\right)$. Therefore, the Wu-Jing expression [Eq. (21) in Ref. 4] for the relation between the powder and solid Hugoniot under isobaric conditions reduces to $V_{H}^{\prime}=V_{H}+(R / 2)\left(V_{00}-V_{0}\right) /(1-R / 2)$, where

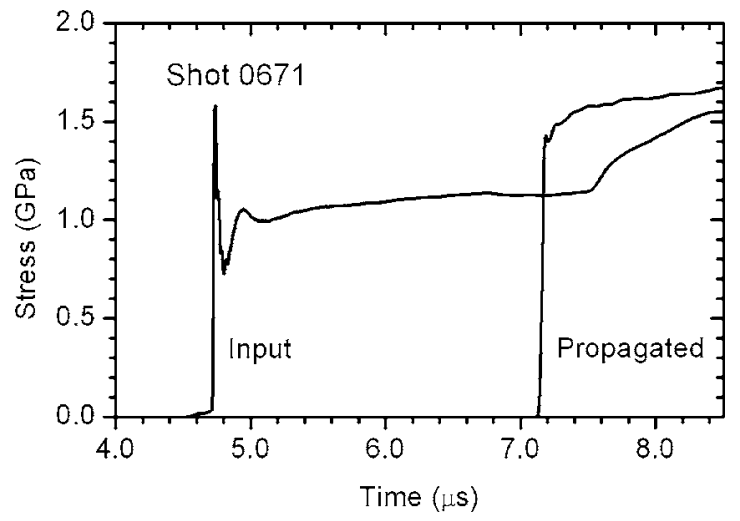

FIG. 2. Typical stress-time traces recorded by the respective input and propagated gauges.

$V_{H}^{\prime}$ and $V_{H}$ are the specific volumes on powder and solid Hugoniot at isobaric conditions, respectively, $V_{00}$ and $V_{0}$ are the specific volumes of powder (compact) and solid at initial conditions, respectively, and $R$ is a pressure-dependent parameter. ${ }^{4}$ For case (b), $Y$ was obtained by fitting the quasistatic data using $P$ - $\alpha$ model $^{9}$ and $P_{1}$ was obtained from the measured input stress traces. The elastic critical pressure of the powder compact $P_{\text {crit }} \approx 0.72 \mathrm{GPa}$ was estimated using $P_{\text {crit }}=(2 / 3) Y \ln \left[\alpha_{0} /\left(\alpha_{0}-1\right)\right] \quad\left(\right.$ where $\left.\alpha_{0}=V_{00} / V_{0}\right)$. ${ }^{4,8}$ Figure 3(a) shows that the predicted Hugoniot of 35\% TMD $25 \mathrm{~nm}$ Fe powder attained from calculations for both cases using the Wu-Jing approach is not consistent with the measured data although the predicted Hugoniot in the range of lower stresses for case (b) seems to be partly compatible with the experimental data at the lower stresses. The predicted Hugoniot for Fe powder of $43 \% \mathrm{TMD}$, however, is in approximate agreement with the experimental data for sintered $\mathrm{Fe}$ (micron-sized grains) of $\sim 43 \% \mathrm{TMD},{ }^{10}$ indicating that the dominating cause for the ineffectiveness of the Wu-Jing approach is most possibly the characteristic properties of $\mathrm{Fe}$ nanopowder, namely, the very large surface energy associated with the internal energy or the abnormally low elastic ("cold") energy. ${ }^{2}$

The measured Hugoniot data, together with the quasistatic data, are plotted against $V / V_{0}$ in Fig. 4 . Figure 4 shows an inflexion from compression to expansion for $25 \mathrm{~nm} F$

TABLE I. Data obtained from Hugoniot experiments for $25 \mathrm{~nm}$ Fe powder of $\sim 35 \%$ TMD. $\rho_{00}$ : prepressed density; $\Delta h$ : sample thickness; $W$ : impact velocity; $\sigma_{x}$ : input stress; $\Delta t$ : transit time; $D$ : shock wave velocity; $u$ : particle velocity; $\rho$ : shock-compressed density; $V=1 / \rho ; V_{0}$ is initial specific volume of Fe solid. $t_{r, \text { ipt }}$ and $t_{r, \text { prop }}$ are the shock rise times of the input and propagated gauges from $10 \%$ to $90 \%$ stress maximum amplitude, respectively. Uncertainties are the standard deviations.

\begin{tabular}{|c|c|c|c|c|c|c|c|c|c|c|c|}
\hline $\begin{array}{l}\text { Shot } \\
\text { No. }\end{array}$ & $\begin{array}{c}\rho_{00} \\
\left(\mathrm{~g} / \mathrm{cm}^{3}\right)\end{array}$ & $\begin{array}{c}\Delta h \\
(\mathrm{~mm})\end{array}$ & $\begin{array}{c}W \\
(\mathrm{~m} / \mathrm{s})\end{array}$ & $\begin{array}{c}\sigma_{x} \\
(\mathrm{GPa})\end{array}$ & $\begin{array}{l}t_{r, \mathrm{ipt}} \\
\text { (ns) }\end{array}$ & $\begin{array}{c}t_{r, \text { prop }} \\
\text { (ns) }\end{array}$ & $\begin{array}{c}\Delta t \\
(\mu \mathrm{s})\end{array}$ & $\begin{array}{c}D \\
(\mathrm{~km} / \mathrm{s})\end{array}$ & $\begin{array}{c}u \\
(\mathrm{~km} / \mathrm{s})\end{array}$ & $\begin{array}{c}\rho \\
\left(\mathrm{g} / \mathrm{cm}^{3}\right)\end{array}$ & $V / V_{0}$ \\
\hline 0655 & $\begin{array}{c}2.760 \\
\pm 0.032\end{array}$ & $\begin{array}{c}2.062 \\
\pm 0.012\end{array}$ & $\begin{array}{c}780 \\
\text { (Cu flyer) }\end{array}$ & $\begin{array}{c}2.5 \\
\pm 0.1\end{array}$ & 8 & 38 & $\begin{array}{c}1.570 \\
\pm 0.018\end{array}$ & $\begin{array}{c}1.313 \\
\pm 0.017\end{array}$ & $\begin{array}{c}0.690 \\
\pm 0.030\end{array}$ & $\begin{array}{c}5.816 \\
\pm 0.301\end{array}$ & $\begin{array}{c}1.350 \\
\pm 0.070\end{array}$ \\
\hline 0661 & $\begin{array}{c}2.758 \\
\pm 0.031\end{array}$ & $\begin{array}{c}2.294 \\
\pm 0.013\end{array}$ & $\begin{array}{c}947 \\
(\mathrm{Cu} \text { flyer) }\end{array}$ & $\begin{array}{c}3.0 \\
\pm 0.1\end{array}$ & 4 & 15 & $\begin{array}{c}1.571 \\
\pm 0.010\end{array}$ & $\begin{array}{c}1.460 \\
\pm 0.012\end{array}$ & $\begin{array}{c}0.745 \\
\pm 0.027\end{array}$ & $\begin{array}{c}5.630 \\
\pm 0.227\end{array}$ & $\begin{array}{c}1.394 \\
\pm 0.056\end{array}$ \\
\hline 0662 & $\begin{array}{c}2.762 \\
\pm 0.029\end{array}$ & $\begin{array}{c}2.350 \\
\pm 0.015\end{array}$ & $\begin{array}{c}1018 \\
\text { (W flyer) }\end{array}$ & $\begin{array}{c}4.2 \\
\pm 0.2\end{array}$ & 3 & 10 & $\begin{array}{c}1.309 \\
\pm 0.006\end{array}$ & $\begin{array}{c}1.795 \\
\pm 0.014\end{array}$ & $\begin{array}{c}0.847 \\
\pm 0.042\end{array}$ & $\begin{array}{c}5.230 \\
\pm 0.240\end{array}$ & $\begin{array}{c}1.501 \\
\pm 0.069\end{array}$ \\
\hline 0663 & $\begin{array}{c}2.756 \\
\pm 0.032\end{array}$ & $\begin{array}{c}2.197 \\
\pm 0.011\end{array}$ & $\begin{array}{c}708 \\
\text { (Cu flyer) }\end{array}$ & $\begin{array}{c}2.1 \\
\pm 0.1\end{array}$ & 10 & 31 & $\begin{array}{c}1.867 \\
\pm 0.023\end{array}$ & $\begin{array}{c}1.177 \\
\pm 0.016\end{array}$ & $\begin{array}{c}0.648 \\
\pm 0.033\end{array}$ & $\begin{array}{c}6.128 \\
\pm 0.400\end{array}$ & $\begin{array}{c}1.281 \\
\pm 0.084\end{array}$ \\
\hline 0671 & $\begin{array}{c}2.748 \\
\pm 0.035\end{array}$ & $\begin{array}{c}2.491 \\
\pm 0.016\end{array}$ & $\begin{array}{c}501 \\
(\mathrm{Cu} \text { flyer })\end{array}$ & $\begin{array}{c}1.1 \\
\pm 0.1\end{array}$ & 7 & 25 & $\begin{array}{c}2.432 \\
\pm 0.010\end{array}$ & $\begin{array}{c}1.024 \\
\pm 0.008\end{array}$ & $\begin{array}{c}0.391 \\
\pm 0.036\end{array}$ & $\begin{array}{c}4.443 \\
\pm 0.260\end{array}$ & $\begin{array}{c}1.767 \\
\pm 0.103\end{array}$ \\
\hline 0672 & $\begin{array}{c}2.729 \\
\pm 0.047\end{array}$ & $\begin{array}{c}2.400 \\
\pm 0.020\end{array}$ & $\begin{array}{c}621 \\
\text { (Cu flyer) }\end{array}$ & $\begin{array}{c}1.4 \\
\pm 0.1\end{array}$ & 5 & 17 & $\begin{array}{c}2.171 \\
\pm 0.016\end{array}$ & $\begin{array}{c}1.105 \\
\pm 0.012\end{array}$ & $\begin{array}{c}0.464 \\
\pm 0.034\end{array}$ & $\begin{array}{c}4.703 \\
\pm 0.268\end{array}$ & $\begin{array}{c}1.669 \\
\pm 0.095\end{array}$ \\
\hline
\end{tabular}



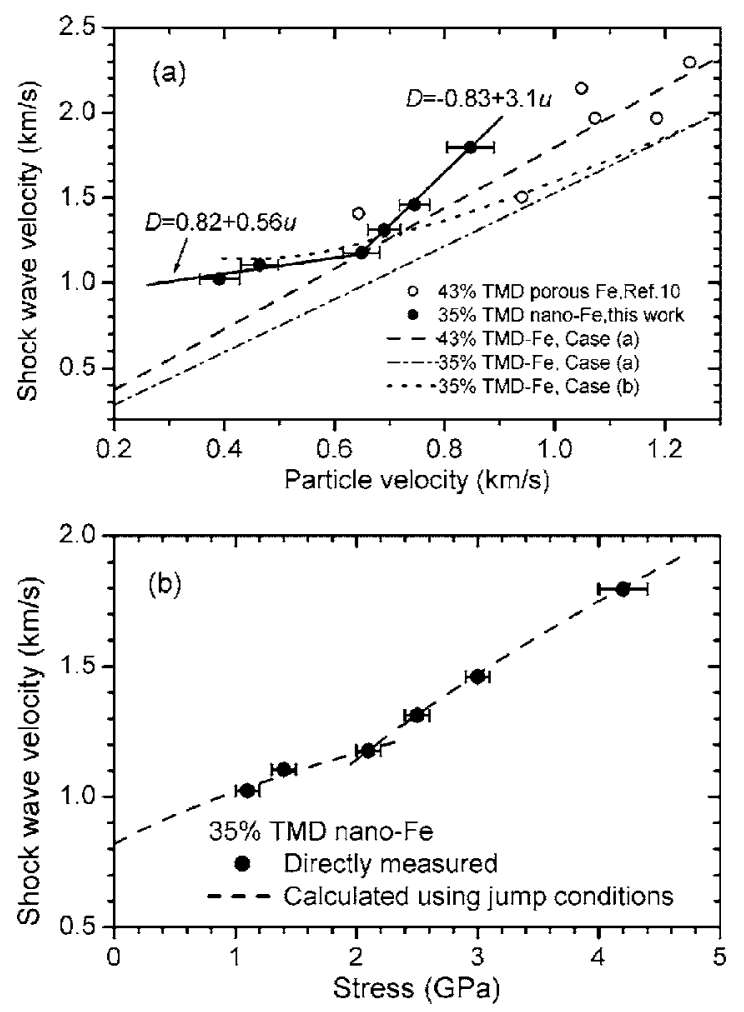

FIG. 3. Measured and predicted Fe-powder Hugoniot. (a) Plot of shock wave velocity vs particle velocity and (b) plot of shock wave velocity vs shock stress.

of $\sim 35 \%$ TMD with increasing shock stress. The lower and upper segments of the Hugoniot are calculated using their corresponding $D(u)$ relations given in Fig. 3(a). Two segments were connected smoothly for the continuity of derivatives at the inflexion. The inflexion on the stress- $V / V_{0}$ plane can be approximately located by utilizing the existence condition of the inflexion, namely, $\left.(d V / d \sigma)_{H}\right|_{\substack{\sigma=\sigma_{i} \\ V=V_{i}}}=0$ (where subscript $H$ denotes the derivative along the Hugoniot and $\sigma_{i}$ and $V_{i}$ are the shock stress and specific volume at the inflexion $i$, respectively). Employing the detailed expression of $(d V / d \sigma)_{H},{ }^{11}$ we acquire $V_{i} / V_{0}=\left(V_{00} / V_{0}\right) \gamma /(\gamma+2)$. For $35 \%$ TMD nano-Fe and obtain $V_{i} / V_{0} \approx 1.3\left[\gamma \approx \gamma_{0}=1.69\right.$ for $\mathrm{Fe}$ (Ref. 10)], which is in good agreement with the experimental results within the uncertainty of measurements (see Fig. 4). The compression-expansion inflexion is mainly attributed to the higher porosity and shock heating., ${ }^{2,12}$ Figure 4 also shows that the measured Hugoniot drastically deviates from the quasistatic data even at lower shock stresses. The possible cause for the deviation is possibly due to the severe difference in stress-loading rate.

In summary, we have measured the Hugoniot of $25 \mathrm{~nm}$ Fe powder of $\sim 35 \%$ TMD using piezoelectric stress gauges. The obtained $D-u$ Hugoniot consists of two distinct segments, with higher slope value in the range of higher stress. The nanopowder Hugoniot cannot be fully predicted using the Wu-Jing model. The applicability of the Wu-Jing model

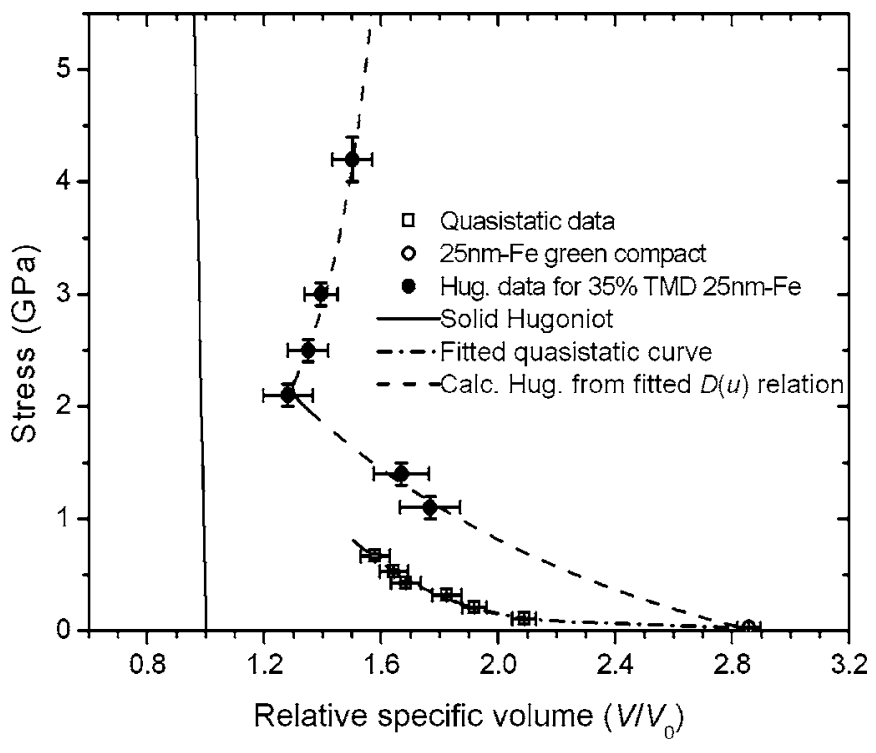

FIG. 4. Plot of measured stress vs relative specific volume $\left(V / V_{0}\right)$ for $25 \mathrm{~nm}$ Fe powder, along with quasistatic data. A compression-expansion inflexion of specific volume with increasing shock stress is observed. The measured Hugoniot data also reveal a deviation from the quasistatic compression path at lower stresses.

for nanopowder Hugoniot prediction can be improved by considering the characteristic properties of nanosized particles. A compression-expansion inflexion in specific volume with increasing shock stress was confirmed for $\sim 35 \%$ TMD $25 \mathrm{~nm}$ Fe powder. The experimental results are particularly valuable for probing the shock compaction of Fe nanopowder, for validating the models for nanopowder Hugoniot prediction, and for modeling the complete equation of state of $\mathrm{Fe}$ over a relatively wide range of density and temperature.

The authors thank M. Martin, A. Fredenburg, L. Ferranti, C. Neel, A. Siddiqi, J. Crawford, J. Amato, and P. Draa for their assistance with experiments and gas gun operation. This work is supported by ONR/MURI under Grant No. N0001405-1-0497.

${ }^{1}$ W. H. Gourdin, Prog. Mater. Sci. 30, 39 (1986).

${ }^{2}$ R. F. Trunin, Shock Compression of Condensed Materials (Cambridge University Press, Cambridge, 1998), p. 63.

${ }^{3}$ R. G. McQueen, S. P. Marsh, J. W. Taylor, F. N. Fritz, and W. J. Carter, in High-Velocity Impact Phenomena, edited by R. Kinslow (Academic, New York, 1970), Chap. VII, p. 293.

${ }^{4}$ Q. Wu and F. Q. Jing, J. Appl. Phys. 80, 4343 (1996).

${ }^{5}$ F. Bauer, IEEE Trans. Ultrason. Ferroelectr. Freq. Control 47, 1448 (2000).

${ }^{6}$ X. Xu and N. N. Thadhani, J. Appl. Phys. 96, 2000 (2004).

${ }^{7}$ M. U. Anderson and R. A. Graham, AIP Conf. Proc. 370, 1101 (1996).

${ }^{8}$ M. M. Carroll and A. C. Holt, J. Appl. Phys. 43, 1626 (1972).

${ }^{9}$ W. Hermann, J. Appl. Phys. 40, 2490 (1969).

${ }^{10}$ LASL Shock Hugoniot Data, edited by S. P. Marsh (University of California Press, Berkeley, CA, 1980), p. 97.

${ }^{11}$ R. K. Linde and D. N. Schmidt, J. Appl. Phys. 37, 3259 (1966).

${ }^{12}$ Ya. B. Zel'dovich and Yu. P. Raizer, in Physics of Shock Waves and Hightemperature Hydrodynamic Phenomena, edited by W. D. Hayes and R. F. Probstein (Dover, Mineola, NY, 2002), p. 713. 